\title{
Polyketal microparticles: a new delivery vehicle for
}

\section{superoxide dismutase}

\author{
Sungmun Lee, ${ }^{\dagger}$ Stephen C. Yang, ${ }^{\dagger}$ Michael J. Heffernan, ${ }^{\dagger}$ W. Robert Taylor, ${ }^{\ddagger}$ and Niren Murthy ${ }^{\dagger}{ }^{*}$ \\ ${ }^{\dagger}$ The Wallace H. Coulter Department of Biomedical Engineering, Georgia Institute of Technology,
} Atlanta, GA 30332.

${ }^{\ddagger}$ Division of Cardiology, Department of Medicine, Emory University School of Medicine, Atlanta, GA 30322

\section{(1) Synthesis of PCADK}

PCADK was synthesized in a $50 \mathrm{~mL}$ two-necked flask, connected to a short-path distilling head. First, $5.5 \mathrm{mg}$ of re-crystallized $p$-toluenesulfonic acid $(0.029 \mathrm{mmol}$, Aldrich), dissolved in $6.82 \mathrm{~mL}$ of ethyl acetate, was added to a $30 \mathrm{~mL}$ benzene solution (kept at $100^{\circ} \mathrm{C}$ ), which contained 1,4cyclohexanedimethanol $(12.98 \mathrm{~g}, 90.0 \mathrm{mmol}$, Aldrich). The ethyl acetate was allowed to boil off, and distilled 2,2-dimethoxypropane (10.94 mL, $90.0 \mathrm{mmol}$, Aldrich) was added to the benzene solution, initiating the polymerization reaction. Additional doses of 2,2-dimethoxypropane $(5 \mathrm{~mL})$ and benzene $(25 \mathrm{~mL})$ were subsequently added to the reaction every hour for 6 hours via a metering funnel to compensate for 2,2-dimethoxypropane and benzene that had been distilled off. After 8 hours, the reaction was stopped by addition of $500 \mu \mathrm{L}$ of triethylamine. The polymer was isolated by precipitation in cold hexane (stored at $-20^{\circ} \mathrm{C}$ ) followed by vacuum filtration. The molecular weight of PCADK was determined by gel permeation chromatography (GPC) (Shimadzu) equipped with a UV detector. THF 
was used as the mobile phase at a flow rate of $1 \mathrm{ml} / \mathrm{min}$. Polystyrene standards from Polymer Laboratories (Amherst, MA) were used to establish a molecular weight calibration curve.

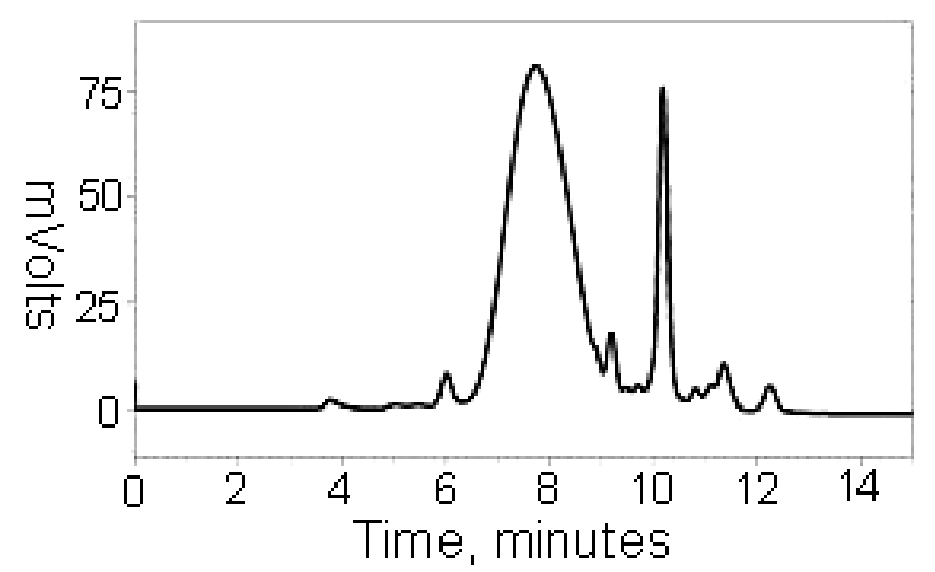

Figure S1. GPC trace of PCADK in THF, Y-axis indicates relative UV absorbance at $262 \mathrm{~nm}, \mathrm{Mw}=$ 6,282 , polydispersity index $(\mathrm{PDI})=1.54$.

\section{(2) Hydrolysis of PCADK}

The hydrolysis of PCADK was measured by ${ }^{1} \mathrm{H}$ NMR in buffered water at the pH values of 1.0 (100 $\mathrm{mM} \mathrm{HCl}), 4.5(100 \mathrm{mM} \mathrm{AcOH})$ and $7.4\left(100 \mathrm{mM} \mathrm{NaH}_{2} \mathrm{PO}_{4}\right)$ at $37^{\circ} \mathrm{C}$. For each time point and $\mathrm{pH}$, three samples were analyzed. For each sample, $20 \mathrm{mg}$ of polymer (ground powder) was suspended in 1 $\mathrm{mL}$ of aqueous solution, at the appropriate $\mathrm{pH}$, and shaken at $120 \mathrm{RPM}$ and $37^{\circ} \mathrm{C}$, using a Labline incubated shaker (Barnstead International, Dubuque, Iowa). At specific time points, the polymer samples were extracted with $1 \mathrm{~mL}$ of $\mathrm{CDCl}_{3}$, and analyzed by ${ }^{1} \mathrm{H} \mathrm{NMR}$, to determine the percent of ketal linkages that were hydrolyzed. Figure S2 describes the changes in the NMR spectrum of the polyketals, after hydrolysis of the ketal linkage. The protons on the methylene group of the intact polyketals are originally at $3.2 \mathrm{ppm}$ and become shifted to $3.5 \mathrm{ppm}$, after hydrolysis of ketal linkage, due to conversion of the ketal group to a hydroxyl. The percentage of ketals hydrolyzed was defined as the ratio of peak integrals at $3.5 \mathrm{ppm}$ to the total integrals of methylene peaks. 


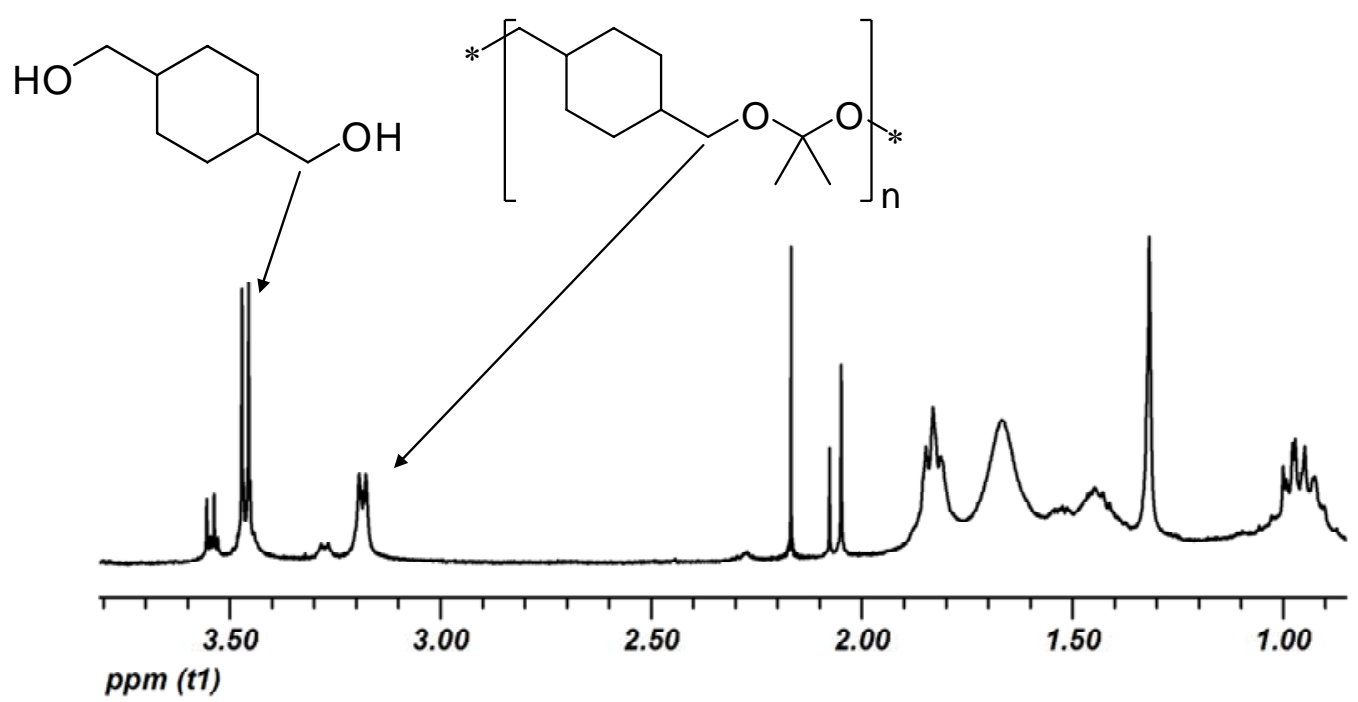

Figure S2. ${ }^{1}$ H-NMR spectrum demonstrating hydrolysis of PCADK. The peaks for the methylene group; protons are shifted from $3.2 \mathrm{ppm}$ to $3.5 \mathrm{ppm}$ after hydrolysis of the ketal to a hydroxyl group.

\section{(3) MTT Reduction Assay}

An MTT (3-(4,5-Dimethylthiazol-2-yl)-2,5-diphenyltetrazolium bromide) reduction assay was performed to measure the toxicity of PCADK microparticles. TIB-186 cells were seeded at a density of $1 \times 10^{5}$ cells/well and incubated in 96-well plates for $24 \mathrm{hrs}$. Cells were treated with PCADK microparticles at various particle concentrations $(100 \mathrm{ng} / \mathrm{mL}-1 \mathrm{mg} / \mathrm{mL})$ and incubated for various durations $(0.5-24 \mathrm{hrs})$. Next, $20 \mu \mathrm{L}$ of MTT solution $(5 \mathrm{mg} / \mathrm{mL}$ in PBS) was added to each well, and the cells were incubated for 2 hours. Then, $200 \mu \mathrm{L}$ of dimethyl sulfoxide (DMSO) was added to dissolve the resulting formazan crystals. After $10 \mathrm{~min}$ of incubation, the absorbance at $585 \mathrm{~nm}$ was measured using an Emax Microplate reader (Molecular Devices, Sunnyvale, CA). Percentage cell viability was calculated by comparing the absorbance of the control cells to that of PCADK microparticle-treated cells. 


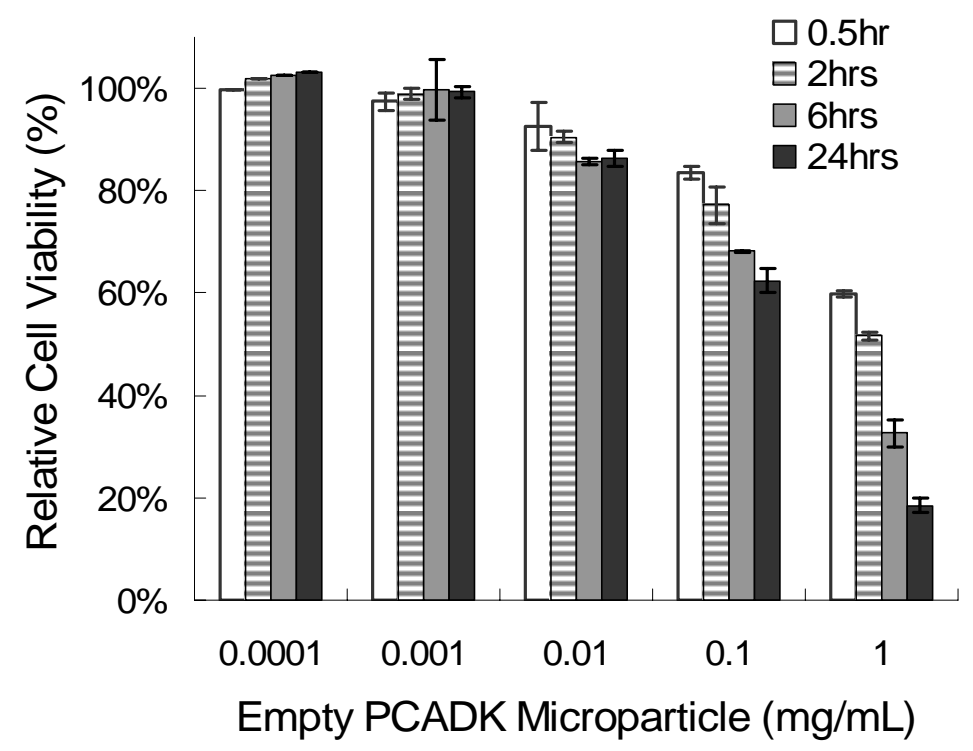

Figure S3. Cell viability of TIB-186 macrophages after incubation with PCADK microparticles; $0.5 \mathrm{~h}$ (white bar), $2 \mathrm{~h}$ (horizontal stripe), $6 \mathrm{~h}$ (gray bar), $24 \mathrm{~h}$ (black bar) for statistical analysis, 3 independent cell viabilities were measured for each sample.

\section{(4) Stability of SOD in PCADK microparticles}

The activity of SOD in PCADK microparticles was determined using an SOD assay kit (Fluka, SOD determination kit 19160, St Louis, MO), using the protocol provided in the kit. These results are presented in Figure S4 and demonstrate that SOD retains its activity after encapsulation within the particles (compare dark versus white bars).

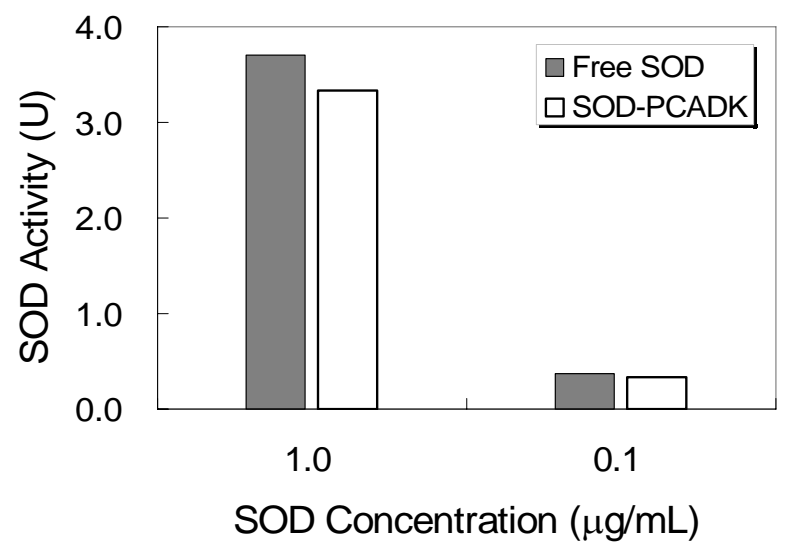

Figure S4. Free SOD (white bar), SOD in PCADK microparticles (dark bar) 